\title{
Towards a Theoretical Framework for Understanding the Development of Media Related Needs
}

\author{
Adam Galpin
}

The Directorate of Psychology and Public Health, University of Salford, Greater Manchester, UK, M6 6PU.

Correspondence to A. Galpin, The Directorate of Psychology and Public Health, University of Salford, Greater Manchester, UK, M6 6PU.

Email:A.J.Galpin@Salford.ac.uk Phone: +44(0)161 2957146

Adam Galpin is a Senior Lecturer in Psychology and co-leads the MSc in Media Psychology at the University and Salford. He obtained his PhD from the University of Nottingham in eyetracking and visual attention, and has since worked in the area of the usability of technology, including the use of media and technology across the lifespan. 


\title{
Towards a Theoretical Framework for Understanding the Development of Media Related Needs
}

\author{
The question of why people select and prefer particular media activities has led to \\ the development of a number of 'needs' approaches to media use. Whilst some \\ frameworks have been developed within the context of media use (e.g. uses and \\ gratifications), others (e.g. Tamborini et al, 2011) look to combine general \\ theories of basic human needs, such as Self-Determination Theory (Deci \&Ryan, \\ 1985) with hedonic gratifications. Drawing on these approaches, a framework is \\ proposed that maps findings from children's and adolescents' media use to four \\ basic human needs: competence, autonomy, relatedness and hedonic needs. The \\ current paper argues that a basic needs approach is useful for understanding how \\ media-related needs emerge and are expressed through development.
}

Keywords: children; adolescents; development; media; needs; self-determination; hedonic

\section{Introduction}

What are the needs of younger users of media and technology and how are they tied to development? The current paper argues that applying a developmental 'needs' approach affords a cohesive framework to organise research findings from lifespan media use. Such approaches to media use assume an active media user whose engagement in various mediated activities reflects the satisfying of particular needs. It might be argued that needs approaches are irrelevant to very young audiences who lack the autonomy to select their own content. However, infants show preferences for media stimuli within the first few months of life (Valkenburg, 2004) thus can exert influence over the activities that caregivers select to keep them entertained and emotionally content.

The idea that media use is driven by human needs is most commonly associated with the Uses and Gratifications (U \& G) framework (Katz, Gurevitch \& Haas, 1973; Katz, Blumler \& Gurevitch, 1974) which views media users as being aware of their own 
needs and able to select media experiences (uses) to satisfy them (gratifications). Whilst early accounts were based on the media of their time (e.g. radio, television, and print), the U\&G approach has been flexibly applied to new media (Sundar \& Limperos, 2013) and is now one of the dominant theoretical traditions within communications sciences.

Whilst U\&G research attempts to identify the range of context-specific needs associated with particular media activities, other approaches classify needs more broadly as hedonic, related to arousal and positive affect, and non-hedonic needs related to the meaningful nature of mediated experiences and how they contribute to our sense of self (Oliver \& Raney, 2011; Tamborini, Bowman, Eden, Grizzard \& Organ, 2010; Tamborini et al, 2011). Tamborini et al's (2010) approach incorporated basic intrinsic needs identified in Deci and Ryan’s influential ‘Self-Determination Theory’ (1985) which proposes that behaviour is motivated by a need for autonomy, to feel competent, and to feel close to and trusted by others (relatedness). Tamborini et al (2011) found that autonomy and competence, in addition to hedonic needs (arousal and affect), predicted enjoyment with both interactive and non-interactive media.

Uses and gratifications research has been applied to specific contexts with younger audiences (e.g. television: Greenberg, 1974; gaming: Sherry, 2013). However, it is argued that a broader approach based on intrinsic human needs subsumes the range of narrower context-specific needs and is therefore more useful to provide an overarching framework for organising media-related needs across development. To this end, the current review synthesises research on media use from birth to adolescence using four intrinsic needs: competence, autonomy, relatedness and hedonic needs.

\section{Competence}

Children are curious from birth (e.g. Harter, 1978) and seek to explore and master their environment (Yarrow \& Messer, 1983). This ‘mastery motivation' can be seen as an 
early expression of the need for competence and is evident from infancy, shown through pride at successful completion of tasks (Dichtner-Blancher, Busch-Rossnagel \& KnaufJensen, 1997). Mastery motivation has also been linked to the television preferences of infants, who are attracted to slow-paced programmes with repetition (e.g. Teletubbies) because the ability to follow storylines and to predict future actions supports a sense of psychological mastery (Valkenburg, 2004). The pride shown by children when completing tasks is strongest when tasks are moderately difficult (Redding, Morgan \& Harmon, 1988). Likewise, children prefer a moderate degree of complexity in relation to their current stage of cognitive development (McCall, Kennedy \& Applebaum, 1977). Indeed, “many developments in children’s media preferences can be explained by the moderate-discrepancy hypothesis” (Valkenburg, 2004, p. 17). The development of cognitive abilities allows comprehension of formal production features and increasingly complex narratives (Anderson \& Hanson, 2010; Kirkorian, Anderson \& Keen, 2012; Pittorf, Lehmann \& Huckauf, 2014) and by pre-adolescence, younger audiences have comprehension schemata to appreciate content aimed at adults (Valkenburg, 2004). However, competence needs remain a motivating force in enjoyment of media activities through a sense of self-efficacy, which predicts persistence with media activities such as gaming (Pintrich \& Schunk, 2002; Sherry et al, 2006).

\section{Relatedness}

The need for social contact is present from birth, demonstrated through instinctive communicative behaviours like crying, and infants possess a social drive to work with others on games and activities (Butler \& Walton, 2013). This increased enjoyment derived from participating in joint activities demonstrates the early emergence of Deci and Ryan’s 'relatedness’ need (feeling close to and trusted by others). Some media 
behaviours are related to these early social drives. Infants' gaze toward the television is influenced by their parent co-viewer, more often looking at the TV when their parent does (Demers, Hanson, Pempek, Kirkorian \& Anderson, 2009). Infants appear to show a preference for baby-directed language on television (Valkenburg, 2004), and children's attention to the TV is influenced by the characters, looking more at children and adult female characters than adult male characters (Schmitt, Anderson \& Collins, 1999). Behaviours indicative of relationships with characters on screen (such as smiling and saying a character's name) are present in toddlers (Lauricella, Gola \& Calvert, 2011) and on-screen characters may come to serve the same purpose as imaginary friends (Gola, Richards, Lauricella \& Calvert, 2013). Parasocial relationships become influenced in middle childhood and pre-adolescence by gender-identity and wishful identification (Hoffner, 1996). Such results suggest that relatedness needs are met through both social contact during media activities and the social actors present in media content.

Research suggests that the way parents mediate their child's viewing changes in middle childhood, with parents offering less explanation around television content in 912 year olds than 5-8 year olds (Valkenburg, Krcmar, Peeters \& Marseille, 1999). Interestingly, the amount of social co-viewing between parents and children did not change across these ages, suggesting that the social contact provided through joint viewing remains important. Research suggests that co-viewing as a family activity continues to be valued in adolescence (Courtois, Merchant, Paulussen, \& Marez, 2011), with some teenagers emphasising the pleasure gained from a cosy evening with the family in front of the television or how ritual family viewing centred around particular programmes (Adriaens, Van Damme, \& Courtois, 2011). Coyne, Padilla-Walker, Fraser, Fellows and Day (2014) found that both parents and adolescents reported that 
social connection and bonding is one reason that families of adolescents use media. So, whilst teenagers may increasingly need their own space (see ‘Autonomy’ section, below), this does not fully replace the relatedness need for family-based activities which are often structured around media routines.

Adolescence is associated with an increasing importance placed on peers which may affect media choices in several ways. Believing peers value certain content leads to higher ratings of that content by adolescents (Berns, Capra, Moore \& Noussair, 2010). Social networking sites allowing the formation and exploration of relationships become an important space for social interactions for adolescents, who associate social networking as a vehicle for maintaining friendships, giving and receiving social support, and forming new relationships (Lenhart, Purcell, Smith \& Zickuhr, 2010). Peer-pressure may also relate to the concept of 'Fear of Missing Out' (or FoMO), defined as a "pervasive apprehension that others might be having rewarding experiences from which

one is absent” (Przybylski, Murayama, DeHaan, Gladwell, 2013, p841). Przybylski et al (2013) found that FoMO decreased with age, and although their youngest respondents were 18, it is reasonable to assume the relationship would be stronger for younger adolescents. The study also showed that those who scored higher on FoMO also engaged more in social media which suggests that FoMO might explain why adolescents are higher users of social media.

\section{Autonomy}

Autonomy needs appear to emerge soon after birth (Leotti, Iyengar, Ochsner, 2010). This is demonstrated first through affective responses to the removal of environmental control, then through exercising choice over recreational activities (evident in preschool children), and later through the need for privacy and freedom of expression (see Helwig, 2006, for an overview). Children begin expressing media preferences from 2 
years (Valkenburg, 2004), and making decisions over media content may therefore provide a domain in which young children can experience a sense of control. Media preferences also relate to a growing sense of personal identity, another key aspect of autonomy. From 5, gender identity becomes more salient. From 7 or 8, children begin to show a preference for characters they can identify with, either the same age or older. By 9, children become increasingly interested in adult content (See Valkenburg, 2004, for a summary).

Striving for autonomy and self-sufficiency are key developmental tasks faced by adolescents and media may begin to take a particularly important role in selfsocialisation for teenagers in domains such as sexuality, romantic relationships and careers (Arnett, 1995). Brown and Pardun (2004) suggest teenagers seek content that tells them about the adult world, and also as a type of 'wishful identification' by seeking aspirational characters. In line with a growing sense of autonomy, teenagers spend increasing amounts of time in their bedrooms, positively related to how media-rich their bedrooms are (Bovill \& Livingstone, 2011). Bedrooms are places for self-expression and allow teenagers autonomy through privacy and secrecy over their activities (Livingstone, 2007; Courtois et al, 2011).

Autonomy involves the development of a personal and social identity which may underpin media choices in myriad ways. Identity may, for instance, determine content preferences. Research suggests that we may seek media that show positive portrayals of our in-group (i.e. positive age-identity portrayals of adolescents) because this increases self-esteem (Mares and Sun, 2010). The internet may support the exploration of identity by allowing adolescents to "slide in and out of various possible selves” (Borca, Bina, Keller, Gilbert, \& Begotti, 2015, p. 50). Social media platforms in particular offer different avenues for identity exploration and self-expression. One 
reason these platforms have rapidly changed the media landscape as well as the social landscape in young people is that they offer a social space to project and manage an identity.

\section{Hedonic Needs}

Hedonic needs are met through pleasurable emotional experiences, optimal levels of arousal, and the avoidance of negative affect. Evidence suggests media use may be influenced by mood in very young audiences. For example, pre-school boys who had been interacted with in a hostile way watched nurturing content for longer than a less nurturing program (Masters, Ford \& Arend, 1983). This demonstrates an early example of using media for 'mood management' (Zillman, 1988) which predicts that media is used to regulate arousal through relieving boredom or over-stimulation. Likewise, an early study of television uses and gratifications in children (Rubin, 1977) found that passing time, arousal and relaxation were the most important motivations in 9, 13 and 17 year olds. Sensation seeking is associated with video game play in $9-13$ year olds, evidencing the use of media activities to relieve boredom (Jensen, Weaver, Ivic \& Imboden, 2011). The drive for arousing experiences peaks in adolescence which may explain why younger adults compared to older adults are more hedonistic in their media choices, seeking arousing content such as horror movies (Johnston, 1995). Further evidence for mood management finds that television is a way for adolescents to release tension that results from conflict within the family home (Roe \& Minnebo, 2007).

\section{Conclusion}

This review argues that the choices and preferences of younger media users can be usefully considered as reflections of the way that basic human needs are expressed through development. The synthesis of competence, relatedness, autonomy and hedonic 
needs is successful in explaining many developmental aspects of media use. The approach may provide a new way of evaluating the success of particular mediated experiences at different developmental stages. The success of social networks with adolescents, for instance, makes sense if considered in relation to how identity exploration and peer connection are expressions of autonomy and relatedness needs, respectively. Touch-screen technologies may be successful with infants because they support a sense of autonomy through immediate sensori-motor contingencies. Such an approach may be useful in a rapidly changing media universe because whilst technological affordances change our uses and gratifications, the basic human needs that drive them will remain constant.

Acknowledgements: The author received financial support from the British Broadcasting Corporation during the writing of this commentary.

\section{References:}

Adriaens, F., Van Damme, E. \& Courtois, C. (2011). The spatial and social contexts of television-viewing adolescents. Poetics, 39(3), 205-227.

Arnett, J.J. (1995). Adolescents' uses of media for self-socialization. Journal of Youth and Adolescence, 24(5), 519-533.

Anderson, D.R. \& Hanson, K.G. (2010). From blooming, buzzing confusion to media literacy: The early development of television viewing. Developmental Review, 30, 239255.

Berns G.S., Capra C.M., Moore S., \& Noussair, C. (2010). Neural mechanisms of the influence of popularity on adolescent ratings of music. NeuroImage, 49, 2687-96. 
Borca, G., Bina, M., Keller, P.S. Gilbert, L.R. \& Begotti, T. (2015). Internet use and developmental tasks: Adolescents’ point of view. Computers in Human Behaviour, 52, 49-58.

Bovill, M., \& Livingstone, S. (2001). Bedroom culture and the privatization of media use. In: M. Bovill and S. Livingstone. (Eds.) Children and Their Changing Media Environment: A European Comparative Study (pp. 179-200). Mahwah, NJ: Lawrence Erlbaum Associates.

Brown, J.D., \& Pardun, C.J. (2004). Little in common: Racial and gender differences in adolescents’ television diets. Journal of Broadcasting \& Electronic Media, 48, 266278.

Butler, L.P. \& Walton, G.M. (2013). The opportunity to collaborate increases preschoolers' motivation for challenging tasks. Journal of Experimental Child Psychology, 116, 953-961.

Courtois, C., Merchant, P., Paulussen, S. \& Marez, L.D. (2011). The triple articulation of media technologies in teenage media consumption. New Media and Society, 14(3), 401-420.

Coyne, S.M., Padilla-Walker, L.M. Fraser, A.M., Fellows, K. and Day, R.D. (2014). "Media Time = Family Time": Positive media use in families with adolescents. Journal of Adolescent Research, 29(5) 663-688.

Deci, E. L., \& Ryan, R. M. (1985). Intrinsic Motivation and Self Determination in Human Behavior. New York: Plenum.

Demers, L.B., Hanson, K.G.,Pempek, T.A., Kirkorian, H.L. \& Anderson, D.R. (2009). Following the leader: A social component to infant attention to baby videos? Poster presented at the biennial meeting of the society for research in child development, Denver, CO. 
Dichter-Blancher, T.B., Busch-Rossnagel, N.A. \& Knauf-Jensen, D.E. (1997). Mastery motivation: Appropriate tasks for toddlers. Infant Behaviour and Development, 20(4), 545-548.

Gola, A.A.H., Richards, M.N., Lauricella, A.R. \& Calvert, A.L. (2013). Building meaningful parasocial relationships between toddlers and media characters to teach early mathematical skills. Media Psychology, 16, 4, 390-411.

Greenberg, B. S. (1974). Gratifications of television viewing and their correlates for British children. In J. G. Blumler \& E. Katz (Eds.), The uses of mass communications: Current perspectives on gratifications research (pp. 71-92). Beverly Hills, CA: Sage. Harter, S. (1978). Effectance motivation reconsidered: Toward a developmental model. Human Development, 1, 661-669.

Helwig, C.C. (2006). The development of personal autonomy throughout cultures. Cognitive Development, 21, 458-473.

Hoffner, C. (1996). Children's wishful identification with and parasocial interaction with favorite television characters. Journal of Broadcasting \& Electronic Media, 40, 389-402.

Jensen, J.D., Weaver, A.J., Ivic, R. \& Imboden, K. (2011). Developing a brief sensation seeking scale for children: Establishing concurrent validity with video game use and rule-breaking behavior, Media Psychology, 14(1), 71-95.

Johnston, D.D. (1995). Adolescent's motivations for viewing graphic horror. Human Communication Research, 21, 522-552.

Katz, E., Blumler, J., Gurevitch, M., (1974). Utilization of mass communication by the individual. In Blumler, J., Katz, E. (Eds.), The Uses of Mass Communication Current Perspectives on Gratifications Research (pp. 12 - 34). Beverly Hills, CA: Sage. 
Katz, E., Gurevitch, M., Haas, H., (1973). On the use of the mass media for important things. American Sociological Review, 38, 164-181.

Kirkorian, H.L., Anderson, D.R. \& Keen, R. (2012). Age Differences in Online Processing of Video: An Eye Movement Study. Child Development, 83, 2, 497-507.

Lauricella, A. R., Gola, A. H., \& Calvert, S. L. (2011). Toddlers’ learning from socially meaningful video characters. Media Psychology, 14, 216-232.

Lenhart, A., Purcell, K., Smith, A., \& Zickuhr, K. (2010). Social media \& mobile internet use among teens and young adults. Retrieved from the Pew Internet \& American Life Project website: <http://www.pewInternet.org/2010/02/03/social-mediaand-young-adults/>.

Leotti, L.A. Iyengar, S.S Ochsner, K.N. (2010). Born to choose: the origins and value of the need for control. Trends in Cognitive Sciences, 14(10), 457-463.

Livingstone, S. (2007). From family television to bedroom culture: Young people's media at home. In E. Devereux (Ed.), Media Studies: Key issues and Debates (pp. 302321). London: Sage.

Mares, M-L. \& Sun, Y. (2010). The multiple meanings of age for television content preferences. Human Communication Research, 36, 372-396.

Masters, J., Ford, M., \& Arend, R. (1983). Children’s strategies for controlling affective responses to aversive social experience. Motivation and Emotion, 7(1), 103-116.

McCall, R.B., Kennedy, C.B. \& Applebaum, M.I. (1977). Magnitude of the discrepancy and the distribution of attention in infants. Child Development, 48, 772-786.

Oliver, M.B. \& Raney, A.A. (2011) Entertainment as pleasurable and meaningful: Identifying hedonic and eudaimonic motivations for entertainment consumption. Journal of Communication, 61(5) 984-1004. 
Pintrich, P.R., \& Schunk, D.H. (2002). Motivation in education Theory, research, and applications. Upper Saddle River, NJ Prentice-Hall.

Pittorf, M.L., Lehmann, W. \& Huckauf, A. (2014). The understanding of pans in $3-6$ year-old children. Media Psychology, 17(3), 332-355.

Przybylski, A.K., Murayama, K., DeHaan, C.R., Gladwell, V. (2013). Motivational, emotional, and behavioural correlates of fear of missing out. Computers in Human Behaviour, 29, 1841-1848.

Redding, R. E., Morgan, G. A., \& Harmon, R. J. (1988). Mastery motivation in infants and toddlers: Is it greatest when tasks are moderately challenging? Infant Behaviour and Development, 11, 419-430.

Roe, K. \& Minnebo, J. (2007). Antecedents of adolescents’ motives for television use. Journal of Broadcasting and Electronic Media, 51(2), 305-315.

Rubin, A.M. (1977) Television usage, attitudes and viewing behaviors of children and adolescents, Journal of Broadcasting, 21(3), 355-369.

Schmitt, K.L., Anderson, D.R. \& Collins, P.A. (1999). Form and content: Looking at visual features of television. Developmental Psychology, 35(4), 1156-1167.

Sherry, J. L., Rosaen, S., Bowman, N. D., \& Huh, S. (2006, June). Cognitive skill predicts video game ability. Paper presented at the annual meeting of the International Communication Association, Dresden, Germany.

Sherry, J. L. (2013). The challenge of audience reception: A developmental model for educational game engagement. In F. C. Blumberg \& S. M. Fisch (Eds.), Digital Games: A Context for Cognitive Development. New Directions for Child and Adolescent Development, 139, 11-20.

Sundar, S.S. \& Limperos, A.M. (2013). Uses and Grats 2.0: New gratifications for new media. Journal of Broadcasting \& Electronic Media, 57(4), 504-525. 
Tamborini, R., Bowman, N. D., Eden, A., Grizzard, M., \& Organ, A. (2010). Defining media enjoyment as the satisfaction of intrinsic needs. Journal of Communication, 60, 758-777.

Tamborini, R., Grizzard, M., Bowman, N.D., Reinecke. L., Lewis, R.J. \& Eden, A. (2011). Media enjoyment as need satisfaction: The contribution of hedonic and nonhedonic needs. Journal of Communication, 61, 1025-1042.

Valkenburg, P.M. (2004). Children's Responses to the Screen: A Media Psychological Approach. New Jersey: Lawrence Erlbaum Associates.

Valkenburg, P.M. Krcmar, M., Peeters, A.L. \& Marseille, N.M. (1999) Developing a scale to assess three styles of television mediation: "Instructive mediation," "restrictive mediation," and "social coviewing". Journal of Broadcasting \& Electronic Media, 43(1), 52-66.

Yarrow. L. J. \& Messer, D. J. (1983). Motivation and cognition in infancy. In M. Lewis (Ed.). Origins of Intelligence: Infancy and early childhood. New York: Plenum.

Zillmann, D. (1988). Mood management through communication choices. American Behavioral Scientist, 31, 327-340. 